\title{
Security in transition(s): The low- level security politics of electric vehicle range anxiety
}

Security Dialogue 2019, Vol. 50(6) 547-563

(C) The Author(s) 2019

Article reuse guidelines: sagepub.com/journals-permissions DOI: 10.1 177/09670106/987/443 journals.sagepub.com/home/sdi

@SAGE

\author{
Johannes Kester \\ University of Aarhus, Denmark \\ University of Oxford, UK
}

\begin{abstract}
By drawing on critical security studies in the context of a sociotechnical transition, this article calls for more attention to the presence and sometimes alternative use of mostly unobserved security practices in the materialization of everyday consumer goods and services. This call is illustrated through a discussion of the phenomenon of range anxiety and the intra-action between drivers of electric vehicles (EVs), designers, and algorithms that observe, estimate and nudge the remaining range of an EV. Inspired by Foucault and Barad, the range-anxiety discussion offers four alternative security insights. First, it supports an argument to include stress as an embodied instance of insecurity. Second, it draws attention to a security apparatus that is based on a constantly expanding assemblage around range estimates. Third, it shows how this apparatus rests on a novel algorithm that has a continuous instead of a binary output and is governed by a distributed sovereignty: where the driver simultaneously is the object of measurement, subject of governance for more efficient driving and the ultimate sovereign who decides on the trip. Lastly, the discussion highlights how range estimates not only mediate the materialization of EVs and their automobility but also (re)perform epistemological or ontological forms of uncertainty.
\end{abstract}

\section{Keywords}

Algorithm, electric vehicles, insecurity, observation, range anxiety, security apparatus

\section{Introduction}

The transition in personal transport from vehicles powered by internal combustion engines to electric vehicles (EVs) is not the first topic that comes to mind when discussing critical security studies, and yet security practices, logics and arguments permeate this transition at all levels of decisionmaking. This is most obvious on a grand political stage, where concerns about climate security (IRENA, 2018), local health (Buekers et al., 2014) and fossil-fuel dependency (IEA, 2018) drive the transition forward. In turn, security concerns also emerge from the transition: such as the 
additional load on local electricity grids (Habib et al., 2015), the social and environmental impacts of battery production (McManus, 2012), or the potential traffic safety consequences of near-silent propulsion (Genechten and Berkhoff, 2014).

However, there are other ways in which security returns in sociotechnical systems. In the case of electric mobility, one example includes the phenomenon of range anxiety: the everyday fear of drivers to run out of fuel and/or electricity before they reach their destination or a refuelling or recharging station. While a limited issue for internal combustion engine vehicles, the average battery capacity of (early) EVs has resulted in limited range perceptions, which makes range anxiety a prevalent theme in the transition debate on electric mobility among consumers and policymakers (Graham-Rowe et al., 2012; Liao et al., 2017; Noel et al., 2019; Rezvani et al., 2015). To mitigate this anxiety, engineers, designers and drivers seem to forward three sets of responses. There is a desire to improve the physical range of EVs through higher-capacity batteries and more energyefficient vehicles. Alternatively, range anxiety is mitigated through investments in more and higher-capacity public charging infrastructure, so that drivers can recharge their vehicles more conveniently and faster. While these are two of the most discussed and financed options, EV range anxiety is also moderated through an optimization of the algorithms that calculate the remaining range. The idea is that a 'better' range estimate would already improve consumer willingness to buy EVs and concomitantly reduce the resource drain that comes with a perceived need for longerrange and thus heavier and larger EVs, as well as potentially redundant charging points (Rauh et al., 2017).

Unfortunately, even though the empirical ground of critical security studies 'has flourished' (Aradau et al., 2015b: 1) and now includes attention to, inter alia, critical infrastructure (Aradau, 2010; Coward, 2009), health and disease (Elbe et al., 2014; Voelkner, 2011), climate change (Corry, 2012; Methmann and Rothe, 2012), or the importance of materiality (Amicelle et al., 2015; Salter, 2016), most focus remains centred on bordering, terrorism, migration and defence issues. There is surprisingly little attention to the security practices governing, for instance, natural resources, transport and the built environment, let alone their sociotechnical transitions (Forman, 2018; Kester, 2018a). Few studies, extending Huysmans's (2011) discursive interpretation, engage with the presence and alternative use of 'little security nothings' or low-level unobserved security practices in the interconnected systems that supply and make possible a modern way of life.

The argument put forward in this article is that critical security studies can benefit from engaging with atypical and low-level security practices, such as range anxiety, in sociotechnical systems. For example, as illustrated below, the engagement in this article with range anxiety offers a particular novel instance of insecurity based on a stress logic. In addition, the range algorithms are shown to fit a Foucauldian notion of security and help govern a particular personal form of (auto)mobility, even though they are practised by non-security individuals and relatively hidden from popular discourse. That these algorithms are obscured from view does not make them irrelevant. Empirically, they affect the transition towards a more sustainable form of automobility. What's more, theoretically, not only are there precedents for studying such everyday security practices around automobility, there is also a clear theoretical grounding in Foucault to engage with sociotechnical systems more broadly, just as a quick glance at the literature around sociotechnical systems already hints at potentially novel security insights.

First, there are precedents of security analysis around (auto)mobility. Among others, these include the Foucauldian-inspired work by Campbell (2005) on automobility wherein he discusses how the design of national fuel economy standards and the individual consumer choice for safer vehicles promote sports utility vehicles (SUVs) with their relatively high fuel consumption, and how this in turn connects the USA strategically with the Middle East. Specifically, Campbell (2005: 967) writes how 'the SUV draws the understanding of security as sizeable enclosure into 
daily life, folds the foreign into the domestic, and links the inside to the outside'. Paterson and Dalby (2006: 11), in turn, study the security and control imagery and language of car adverts to highlight the subjects that are produced in the interaction between security, automobility and underlying discourses about US oil imperialism, (technocratic) ecological modernization and carboniferous capitalism (sales based on cheap fuel): from conquering nature and the world or winning collisions with smaller vehicles, to new heads-up displays that 'connect the car symbolically to a set of technologies of surveillance'. In relation to more general mobility, Adey and Anderson (2011) analyse the air-traffic risk assessments around the volcanic eruption on Iceland, and Paterson (2014) illustrates how the construction of carbon markets, themselves 'mobile', are meant to limit the circulation of carbon dioxide and thereby other physical forms of mobility, including transportation.

Second, building on these examples and their use of Foucault, there is a theoretical argument why critical security studies for its own sake should engage with the transitions in sociotechnical systems. As already put forward by Dillon (2005), Foucault's reframing of security towards the governance of circulation is especially apt for studying modern sociotechnical systems producing and transporting commodities, people, data and money, in part because Foucault's notion of security as biopolitics - the indirect milieu-oriented and mediating form of security governance that does not govern subjects directly but guides the flows of people and goods through a dispersed political economy of natural and artificial matter, scales, regulations, market mechanisms and subjects' desires - derives largely from his analysis of urban mobility and the open circulation of scarce food supplies (Foucault, 2007). Dillon (2005) subsequently highlights the political challenges that stem from such a move, including the politics of differentiating between desirable and undesirable circulations and the appropriate level of intervention in circulations. Additionally, Aradau and Blanke (2010) argue that a focus on circulation without production is incomplete. As they state, while 'circulation has become increasingly important for security governance as crisis manifests itself in circulation', 'crises themselves have their roots in production, independent of their manifestation' (Aradau and Blanke, 2010: 54). Given that the politics around sustainable transitions, to different degrees, explicitly mediate production and consumption crises through a governance of their respective circulations, they are less vulnerable to this critique and could offer insight into alternative security practices and strategies.

Third, a quick security engagement with sociotechnical systems in the transition literature (Geels et al., 2017) and science and technology studies (Callon, 1986), as well as the recent crossover between critical security studies and the mobility literature (Aradau, 2016; Leese and Wittendorp, 2018), readily points to three alternative reflections on security and thus an empirical benefit for critical security studies to engage with these systems. For example, such a focus illustrates instances whereby security is used by some, at certain times and in certain contexts, to favour a specific sociotechnical transition over others, and subsequently helps materialize a particular sociotechnical system for decades to come (Mitchell, 2013). Next, it highlights the extensive materiality and interconnectedness of the sociotechnical systems behind natural resources, consumer goods and waste streams, where it is not one unit within the flow of goods, people or data that is deemed risky or at risk but the complete system that enables the circulation, including its in- and outputs, implying that the smallest elements are just as important (and as responsible) as the overall system (Bennett, 2005). Likewise, a focus on nodes of security, the go/no-go moments when a person or good is allowed to continue its journey at borders and other checkpoints, does not completely cover the security practices governing the in-betweenness of the circulation of natural resources (Forman, 2018).

The argument that range anxiety offers an atypical yet insightful example of security governance rests on the assumption that it is necessary to take seriously the notion that 'contemporary 
politics have become "saturated by "security"," (De Larrinaga and Doucet, 2010: 1, quoting Neocleous, 2008: 2). Theoretically and methodologically, this seems to have been accepted after the shift from a focus on content to conceptual definitions of security (Baldwin, 1997), to normative readings (Booth, 2007) and ever more encompassing theoretical (Bigo, 2014; Buzan et al., 1998; Dillon, 2010) and methodological approaches (Aradau et al., 2015a; Salter and Mutlu, 2013). Yet it seems that the actual choice for empirics is still primarily policy-given (Coleman and Rosenow, 2016: 213) and self-justified through reference to 'life and death' urgency (e.g. speech acts) or normative critique (Loughlan et al., 2015: 23). However, just as methods predefine what form of security is encountered (Aradau and Huysmans, 2019), empirics also predefine the form and type of (in)security analysed: international military security rests on a threat logic; terrorism studies highlight threat- and risk-based filtration logics; cybersecurity differentiates between 'security' (e.g. a threat logic of third-party access) and safety; energy and food security, among others, highlight differentiation logics; and infrastructure and vital-systems security point to resilience logics (for attempts at more systematic overviews, see Anderson, 2010; Kester, 2018b). An analysis of low-level security practices, like those around range anxiety, offers a least-likely analysis that breaks with such a policy-driven cycle and hence can be used to differentiate between particular instances of insecurity, logics of security and the various ways through which people identify these insecurities.

Specifically, this article draws on a literature review of the academic work on range anxiety and range algorithms, thereby reflecting primarily on a subset of the epistemic community that observes, interprets and acts on range anxiety. The analysis offers four alternative security insights in two steps. In the first step, the article's second section engages with the range anxiety-inspired argument to include stress as an embodied instance of insecurity, continuing early feminist security work (Enloe, 2014) that links perceived future threats with present bodily responses. The subsequent three sections analyse the range algorithm. The third section highlights the inclusionary assemblage around range algorithms that mitigates range anxiety and helps materialize particular EVs and recharging infrastructure. The fourth section, in line with the security literature on algorithms (Amoore and Raley, 2017), draws attention to a security apparatus based on an inclusionary algorithm (taken broadly to include both the algorithm and its electronics, sensors, display and output) that has a continuous and ambiguous output instead of a binary result. Furthermore, this inclusionary algorithm stands out from the stricter security-subject relationships in critical security studies as it is governed by a negotiated and partly distributed sovereignty (e.g. locus of decisionmaking). The fifth section offers an analysis of how the performative nature of the range algorithm not only has the potential to mediate the construction of EVs and charging infrastructure, but also informs a particular understanding of uncertainty through options that advance either epistemological or indeterminate forms of uncertainty. Lastly, the conclusion summarizes and reflects on the preceding discussions.

\section{Stressing about range as an instance of insecurity}

'Range anxiety' is the term used to describe the fear of car drivers that their vehicle might run out of fuel or electricity before they reach their destination. Basically, current petrol and diesel cars have the energy capacity to drive anywhere from 600 to $1200 \mathrm{~km}$ depending on the car model and fuel-tank size. In contrast, EVs (those on the road) have an average range of $160 \mathrm{~km}$ (Carbon and Gebauer, 2017), although newer market models offer around 250-300 km, and the most expensive models reach up to $400-500 \mathrm{~km}$ on a single charge. Even though research has shown that a range of $160 \mathrm{~km}$ is sufficient for most daily trips, and for instance covers $87 \%$ of all trips by American drivers (Needell et al., 2016), consumers are seen to respond negatively to the limited range and 
perceive it as a core argument against the purchase and use of EVs (Franke and Krems, 2013b; Liao et al., 2017; Rauh et al., 2017).

Specifically, studies indicate that drivers are prone to overestimate how much they drive on a daily basis and how often they drive longer distances; that drivers are unwilling to see or incapable of seeing that it is possible to use or rent alternatives for longer distances; and that they keep a larger than necessary safety margin because they are not used to cars with such low ranges (Carbon and Gebauer, 2017). Early EV research shows that EV drivers reserved around 20\% (Franke and Krems, 2013a) or even $30 \%$ (Hong et al., 2016) of the total state of charge of an EV to mitigate their uncertainty about the range. Such a safety buffer essentially further reduces the available range of an EV (Franke et al., 2012), which in turn reinforces the desire for vehicles with more range and more charging opportunities.

These factors together lead Rauh et al. (2015: 2) to define range anxiety as 'a stressful experience of a present or anticipated range situation, whereby the range resources and personal resources available to effectively manage the situation (e.g. increase available range) are perceived to be insufficient'. They further argue that the subsequent anxiety or stress shows itself in four ways: cognitively (drivers start to perceive the range and the EV itself negatively), emotionally (drivers feel nervous and fearful), behaviourally (drivers check the range estimate more frequently, adjust their driving style or look for charging opportunities) and physiologically (through increased breathing and heart rates) (Rauh et al., 2015; see also Eisel et al., 2016).

Generally, drivers thus try to prevent stranding with their car. However, Franke et al. (2012: 372) argue that it might not be the actual event that moves people but that 'the avoidance of stress ... characterise[s] range experience more than the experience of stress itself'. This arguably relates to the security literature and its focus on the negation of threats and logics of prevention and precaution (Anderson, 2010; Massumi, 2007), and, by extension, to those activities in the present that are conducted to prevent a potential harmful future (Adey and Anderson, 2012). Furthermore, theoretically, stress links up to, among other things, the literature on emotions and security (Åhäll and Gregory, 2013; D'Aoust, 2013), the everyday experience with insecure situations (Enloe, 2014), and the politics of fear or anxiety (Zevnik, 2017). ${ }^{1}$ Hence, it is possible to see stress, and indirectly range anxiety, as an instance of insecurity, as it represents an intermediate bodily and emotive response to uncertainty, one that people try to avoid.

Interestingly, just as security is an empty signifier to be filled contextually (Beauchamps et al., 2017), range anxiety 'has no consistent psychological definition, but is rather used with different meanings that range from anticipated discomfort to actually experienced fear' (Rauh et al., 2017: 30). Likewise, stress knows 'no solid agreement about the definition . . . as it is a multidimensional construct comprising various components' (Nastjuk and Kolbe, 2015: 2). In contrast to security, however, stress not only activates people but also can be harmful itself, as it is linked to a range of physical and mental health considerations (Nastjuk and Kolbe, 2015; Ursin, 2011).

Furthermore, the stress literature points to a two-stage appraisal of threats that is little discussed in critical security studies. Within the stress literature, range-anxiety scholars follow the transaction model of Lazarus and Folkman (1984), where stress results from the interaction between individuals and their environment. Individuals first interpret an event as something that could negatively impact one's well-being 'in terms of harm (damage already caused by the event), threat (potential of causing future damage), or challenge (ability to effectively overcome the event)' (Eisel et al., 2016: 201). After interpreting and acknowledging the potential negative impacts of an event, people subsequently assess whether they have the resources to cope with such a negative event. The transaction model states that it is only when they do not have this capacity that people experience stress. Stress thus follows a sensed inability to easily counter, adapt to or mitigate a particular insecurity. 
Both Eisel et al. (2016) and Nastjuk and Kolbe (2015) subsequently note that this secondary appraisal in turn is influenced by two elements: the 'locus of control' (Rotter, 1966) and a person's 'self-concept' (Shavelson et al., 1976). The notion of the 'locus of control' relates to the confidence that individuals have in how far they can influence their environment, which in the case of range anxiety translates to the inability of drivers to understand and actively engage with the range algorithm (see the fourth and fifth sections of this article). In turn, 'self-concept' refers to a person's historic experience with similar situations. To improve their self-concept, individuals often strive for more information in order to reduce the uncertainty behind a situation (Eisel et al., 2016; Folkman et al., 1986), which is precisely what is happening in the case of the range algorithms. However, to gather this information, a range of actors and entities first needs to be assembled.

\section{The environment-car-driver entanglement}

With range anxiety identified as an instance of insecurity based on a logic of stress, the next sections look at the security governance around range anxiety, focusing in particular on the range algorithms and the range of persons, sensors, data and artefacts involved and assembled to avoid range anxiety. A quick look shows that there are at least three different groups of human agents actively involved in the gathering of various sociotechnical elements in order to minimize and 'solve' range anxiety, including vehicle engineers, drivers, and human information designers and engineers.

First, vehicle engineers are working hard to increase the actual range of EVs. They do so by adding battery capacity to the cars, by minimizing the power consumption for driving (lower weight, minimal air and road resistance) and by minimizing the energy consumption of a car's secondary elements, such as the heating, ventilation and air conditioning (HVAC) (Eisel et al., 2016; Hong et al., 2016). Alternatively, together with business and public authorities, they increase the charging opportunities and networks, so that the cars can be charged during long-distance journeys. Another popular option are plug-in hybrid vehicles, vehicles that have both electric drivetrains and a traditional internal combustion engine, thereby combining some of the benefits (more range, lower emissions) and downsides of both technologies (heavier vehicles, more maintenance).

Second, the drivers themselves try to minimize range anxiety. Besides an adaptation of their travel routines, lobbying for chargers, and learning when and where to charge, drivers also learn how the peculiarities of an EV, like the range estimate, fit their existing travel routines. Importantly, such practical EV experience does not diminish the perceived range limitations, as drivers still desire more range, but it does ease their range anxiety through improved locus of control and selfconcept (Eisel et al., 2016; Franke and Krems, 2013a; Franke et al., 2012, 2015; Lundström, 2014; Noel et al., 2019; Rauh et al., 2015). For instance, as illustrated below, drivers will start to ignore the range estimate when driving up a slope, knowing that it is incomplete. Theoretically, this implies that the outcome of range estimates can be deemed wrong or untrustworthy, depending on the EV experience and stress vulnerability of the driver.

This actually is where a third group of engineers and designers comes in: those developing the algorithms and visuals behind the dashboards of EVs. For these designers, the goal is to optimize the accuracy of the range estimates and to present them in the best possible way, primarily because the extrapolation of recent consumption levels in conventional vehicle range algorithms is deemed inadequate for EVs. For example, an estimate that stops informing the driver after dipping below the last 100 kilometres, as provided by a 2011 Renault Mégane, ${ }^{2}$ is not an option if your car only drives 160 kilometres. Unfortunately, the first EV range estimates provided similar unreliable outcomes, with drivers reporting unexplainable range drops of $10-20 \%$ and hence dubbing the range algorithm the 'Guess-O-Meter' or 'GOM' in short (Lundström, 2014: 3). 
Even newer EVs struggle. There are numerous online blogs and postings by EV drivers describing how they handle longer distances (Meelen et al., 2019). For example, a blog by bro1999 (2018) details their experience and reflections on a 470-mile roundtrip in a Chevy Bolt (a full EV with a range of 238 miles) $)^{3}$ with a strong elevation, no alternative route around that elevation and limited charging opportunities along the way. With charging at their destination, bro1999 should theoretically have been able to make the trip, but 'I had no clue if those stations would actually be available. Eh, don't sweat the details, right?' Either way, 'Not wanting to roll the dice that I could make it to Pittsburgh on a single charge', the driver 'decided to "top off" the Bolt' for 15 minutes after only 60 miles. In addition,

'I decided to take it easy, driving $60 \mathrm{mph}$ where the speed limit was 70.' The driver then remarks that, 'despite the conservative speeds, I watched my range buffer slowly shrink as the elevation slowly gained. At one point during the drive, my range buffer had been reduced to 4 miles, and if I turned on the HVAC, the estimated miles remaining actually dipped below the "miles to destination" Google Maps in my center display reported.'

In the end, however, the driver arrived with 38 miles to spare. On the way back, after some charging difficulties, the driver reflected on the elevation again and on the 'humid and chilly' weather:

'Each time I turned on the defroster, precious electrons were zapped from my battery. About halfway into my 177-mile leg, the Bolt's GOM spit out a number that was 8 miles less than the miles I still needed to drive. I knew that soon I would start a descent down from my current 2,500 elevation, but seeing a range number less than the miles-to-go number is always unnerving.'

After arriving home, the driver closes his blog by discussing the lessons of ' a not completely stressfree trip', pointing in particular to the inadequate yet slowly improving charging infrastructure, but also remarking that 'for those of us willing to be adventurous and take a little risk, there is no need to wait to embark on those road trips'. In fact, 'being worried about running out of range is great for keeping you awake during a graveyard shift drive!'

Besides discussing the need for public charging infrastructure, this blog uses stress and risk language to describe a constantly moving range estimate and how it is influenced by elevation levels, driving speeds and weather conditions. The third group of engineers and designers take these concerns seriously and focus on improving the range estimates. They do so, on the one hand, by optimizing the internal controls and algorithms of the car to better predict the power consumption and electricity regeneration capacity (when braking) at particular speeds (Hong et al., 2016; Tannahill et al., 2015), and, on the other, by including ever more variables into the range algorithm, including factors like weather conditions, traffic conditions and upcoming charging opportunities (De Weerdt et al., 2016), the driver's driving style, speed limits, and the actual topology of the roads along the trip (such as the slope, curvatures, and number of starts and stops) (Birrell et al., 2014; Eisel et al., 2016; Neaimeh et al., 2013; Pi et al., 2016).

Theoretically, this desire to gather ever more 'variables' into the algorithm points to a clear gathering and entanglement of human and material elements into an assemblage that shapes the information systems that are constructed to mitigate range-anxiety concerns. These elements include the actors trying to mitigate range anxiety, the algorithm and sensors, the car and its construction, and the variables mentioned above. While traffic is a social scarcity event à la Hirsch (1976), in that higher levels of road use lead to a lower use value of those roads (due to traffic congestion, etc.), and traffic rules are meant to mediate between drivers to optimize the use value and safety of roads, the interaction between drivers and their traffic environment has always been more about a range of individuals observing their environment in an almost Luhmannian fashion of individual systems 
observing their outside environment (see Luhmann, 2006). The new inclusionary range algorithms of EVs break with that directionality, as observer and environment become part of each other in line with the entanglement and assemblage literature (Barad, 2007; Bennett, 2005; Latour, 1996).

While it is outside the scope of this article to engage with the entanglement and assemblage literature, a shared key insight across its various theoretical approaches is that humans, hybrids and non-humans all possess the capacity to effect change. As such, humans, hybrids and non-humans can act performatively, a term that describes 'a set of processes that produce ontological effects, that is, that work to bring into being certain kinds of realities or . . . that lead to certain kinds of socially binding consequences' (Butler, 2010: 147). The range algorithm, as a performative hybrid assemblage of human and non-human variables, thus can be said to perform particular instances of electric mobility. For example, it mediates the desire for additional battery capacity, which leads to heavier and larger vehicles, and consequently increases the environmental footprint of EVs (Rauh et al., 2017). It also changes the road infrastructure as it potentially lowers the desire for more and faster charging equipment: the number of public accessible stations, their placement (including rest areas), and their capacity or the speed with which one can charge (Kester, 2018a; Urry, 2004).

\section{Observing, informing and conducting drivers}

Interestingly, the range algorithms effect the above-mentioned changes primarily through observation and knowledge dissemination. Hence, as discussed below, they are not only part of a security apparatus based on an 'exhaustive surveillance' biopolitics of knowledge production with its differential 'normality curves' of at-risk subjects within a population (Foucault, 2007: 8, 63, 68), but also fit the phenomenology of Barad (2007). The latter allows non-human elements to influence humans through an active role in the practice of observation. Specifically, Barad argues that nonhuman assemblages, like the range algorithm, are part of the boundary-drawing practices that perform certain material-discursive realities as they help define what people actually observe. Basically, sensors and algorithms extend human levels of observation and thereby extend our 'already broad cognitive function of thought' on the world (Amoore and Raley, 2017: 5). But, as Barad argues, this implies that human observation is always already mediated. In other words, range algorithms are performative because they extend human observation when they measure, filter and calculate the range estimate faster and with a wider input than humans could and subsequently, through their output, help conduct the conduct of drivers: how they drive (speed and style), where they drive, when they drive, how far they drive, what they drive, and so on.

However, in contrast to more binary-oriented security algorithms, like Homeland Security's Automated Targeting System (ATS), which has a rather strong knowledge discrepancy between the travellers and the security officials (Amoore and De Goede, 2008), the range algorithm highlights an interesting position of the driver as both an object of measurement, subject of nudging and final observer of the estimate.

First, the driver is an object of measurement, as the use of 'hotel services' like HVAC and the driving style of the chauffeur are user-based elements that affect the range of an electric car besides the vehicle and its environment (Bingham et al., 2012; Birrell et al., 2014). Research shows that aggressive driving directly equates with a higher power consumption and thus a reduced range, and indirectly is also responsible for a lower accuracy of the range estimates (Bingham et al., 2012). Interesting from a Foucauldian perspective is that aggressive driving is translated by Bingham et al. (2012) as a driving style with a power consumption that is a standard deviation larger than the average and/or optimal acceleration pattern of 'good driving behaviour' for the specific vehicle model and area. In other words, the driver ideally is monitored as part of the population of EV drivers with a rather strict but still mobile normality curve that differs per vehicle and region. 
Besides actively monitoring driving styles, designers gradually also attempt to increase the accuracy of the range estimates by identifying drivers with the help of user profiles and separate (personalized) keys or through the actual attribution of driving styles and trips to specific drivers. While currently still primarily aimed at convenience (automatic seat adjustment, music profiles, etc.) or used to gain access to shared vehicles (via smartphone apps), such forms of identification do open the road to differentiated insurance provisions and mobility tracking.

Second, the driver is subject to the algorithm's output. For example, some designers think about the presentation of the estimates (Lundström, 2014), partly for safety reasons and out of a desire to minimize distractions (Fastrez and Haué, 2008) and partly following studies that found that EV drivers have difficulty understanding the electrical units that are used to describe the energy consumption of an EV (Neumann and Krems, 2016). Here, the focus lies on the actual design of the dashboards and information systems, with engineers and designers adhering to a user-centred design approach about what is presented, when something is presented, and how that is presented in terms of visual, auditory and other potential (haptic) feedback (Fastrez and Haué, 2008; Lundström, 2014; Neumann and Krems, 2016; Strömberg et al., 2011).

However, in order to inspire more energy-efficient driving styles, some suggestions go beyond passive information towards an actual nudging of the drivers through strategic feedback or gamification (Pavlat and Diller, 1993; Pichler and Riener, 2015; Rauh et al., 2015). Comparable to the 'shift gear' advice in conventional vehicles, this includes a nudging based on either the optimal energy use of the vehicle or a comparison with the driving styles of more advanced EV users (Lundström and Bogdan, 2012). In a Foucauldian sense, these designers are thus constructing an algorithm that is actively conducting the conduct of the drivers (Foucault, 2007), as they inform them about the remaining range for the driver's 'self-governance' and actively nudge the drivers by highlighting 'good driving behaviour' taken from the well-behaving part of the EV driver population.

Lastly, while monitored and nudged, drivers still have the final say on the trip. In contrast to the dividing line between travellers and security personnel in ATS, the drivers are the ones to decide on the route and when to charge and stop. Interesting in this respect is that an even-smaller subset of designers and scholars, in contrast to the studies above, explicitly tries to give drivers more control over the algorithm itself. This subset argues against the inclusion of ever more variables into the range algorithm because they principally believe that mobility is inherently uncertain, as no algorithm will ever be able to cover all potentialities of traffic (Franke et al., 2015; Jung et al., 2015). Franke et al. (2015) instead argue that the system should provide drivers with more input options, so that they better understand the parameters and priorities of the range algorithm and can adjust them if desired (thus increasing the driver's locus of control) - in other words, to let the driver decide on what type of journey, driver or driving style the range estimate and journey planner should be based for the next journey.

Theoretically, these aspects of driving style, nudging and adaptability point to a layered number of observations. The above alludes to how drivers observe their road environment and the invehicle information system, how engineers and designers try to render knowable and subsequently visualize the expected remaining range by observing and intervening in the driver-car-environment entanglement, and how the algorithm and its sensors observe the driver, the car and the car's environment. Importantly, both the algorithm, the driver and the engineers have multiple roles in this process, and are at times observer and subject of observation.

The drivers in particular find themselves in an interesting position. In the range-anxiety literature, Franke et al. (2015: 255) argue for the above-mentioned increase in control as 'a fundamental element of any range estimation system for [battery electric vehicles], in the sense of cooperative automation'. They thus see the driver working in tandem with the range algorithm. However, from 
a post-human perspective, one that allows for ontological multiplicity (Mol, 2002), the driver is all these things. The driver simultaneously is an object of the algorithm through driver identification and driving-style measurements, subject to the nudging of the information system to drive more efficiently, and the final sovereign decisionmaker who decides on the duration and route of the trip. In fact, the above shows the driver in a fourth relationship to the model: as a reflexive participant to (and object of) the studies by scholars on the experience of range anxiety and the 'proper' design of the algorithm and in-vehicle information systems.

\section{Range anxiety as a lack of knowledge or indeterminacy}

So far, range anxiety has been identified as an instance of insecurity, and the range algorithm analysed as an instance of security governance based on an inclusionary assemblage and its surveillance-based observational practices that indirectly conduct the conduct of drivers in order to (re) enable a particular individual car-based form of mobility. Noteworthy from a security perspective, however, is that the acceptance of the inherent potentiality of traffic by Jung et al. (2015) and Franke et al. (2015) also informs and performs an alternative understanding of uncertainty that goes beyond the algorithms' performativity of automobility through observational filtrations, simplifications and interventions (Amicelle et al., 2015: 298).

Furthering the argument by Franke et al. (2015) about driver control, Jung et al. (2015) argue that the best way to increase a driver's trust in EV range estimates is not just to increase the accuracy of the range estimate by adding more variables to better reflect the driving conditions, or even to offer drivers more control, but to actually highlight and visualize the uncertainty behind these estimates. In other words, to offer a risk analysis of the probability that the range estimate is correct. They argue that this gives drivers the option to adapt their driving style and/or route if they feel uncomfortable, while it simultaneously prevents drivers from letting their anxiety run amok and exaggerate the safety buffer.

The difference between tackling and accepting uncertainty lies at the heart of range anxiety because the moment that a 'prediction doesn't meet the actual range, the car can be perceived as having misled, or even lied, to the driver' (Jung et al., 2015: 2203, italics in original). In addition, drivers become uncertain as they experience that the range estimate is 'dependent upon factors that both the EV and users themselves could not predict' (Franke et al., 2012: 380). For both these reasons, Jung et al. (2015: 2203) argue that if one highlights and shows the uncertainty, drivers might still experience range anxiety but will 'not lose trust in their vehicle, as the car had not lied to them in the first place'. In contrast to the majority of designers and range-anxiety scholars who see accuracy as a way to gain trust, these authors thus differentiate between accuracy and trust.

Importantly, the differentiation between accuracy and trust points to a second form of uncertainty. Most of the options discussed so far are characterized by an epistemological form of uncertainty whereby range anxiety is approached as a known problem (to be prevented technically with investments in EVs and charging infrastructure) or in terms of a lack of information that needs to be solved through an improvement of the accuracy of the algorithms (adding variables to reflect real-world driving conditions) and improving the feedback to the driver. However, by 'signalling accuracy when in fact there is none' (Jung et al., 2015: 2201), range estimates reinforce the notion that the uncertainty can be known and thus (re)perform this epistemological form of uncertainty (Amoore and Raley, 2017; Lobo-Guerrero, 2012: 128-129).

The alternative trust-based approach instead highlights a more indeterminate understanding of uncertainty. Such an indeterminate uncertainty is not based on a lack of knowledge but on the ontological multiplicity (Mol, 2002) or emptiness (Prozorov, 2016) of the world, where observation acts as the determinant for what becomes real (Barad, 2007). And just as algorithms focusing 
on accuracy (re)perform an epistemological form of uncertainty, range algorithms that differentiate between accuracy and trust perform this indeterminate form of uncertainty and acknowledge that the world is open and continuously (un)folding. The way in which range anxiety is mitigated by non-security specialists thus not only effects (auto)mobility, energy and climate systems, but also more fundamentally how people approach uncertain events and futures.

\section{Conclusion}

This article engaged with electric vehicle range anxiety and the entanglement, observation and uncertainty behind range algorithms as practised by non-security-focused engineers, designers and EV drivers. It linked these to more macro-level debates on sustainable transitions and the sociotechnical system of personal automobility. In doing so, this article offers an analysis of a non-traditional and low-level instance of insecurity and security governance. The conclusion will briefly summarize the two main steps by which this alternative was presented and then offers a 'devil's advocate' reflection to show the importance of such alternative security practices for the field.

First, following earlier work that differentiates between various instances of insecurity, range anxiety was identified as an internalized, embodied and individual instance of insecurity that expresses itself through stress and a desire to avoid the stressful event of stranding with one's car. Even though range anxiety is individually focused and experienced, it has wider social, political and environmental effects, as it is a core reason for car buyers to reject EVs. As such, this potential instance of insecurity affects the sales and use of EVs, and thereby has effects on the speed and direction of the transition to non-fossil-fuel transportation as well as on the design choices, investments and resource use behind EVs and their charging infrastructure. In other words, these 'little individual insecurity nothings' add up.

Second, the subsequent sections on the entanglement, observation and uncertainty behind range algorithms presented a security apparatus based on an hybrid assemblage that helps to (re)enable electrified automobility as it monitors drivers and their environment through ever more variables, places them within a normality curve of the EV driver population, and then informs, guides and nudges them to more energy-efficient driving styles, route choices and charging behaviour. In contrast to existing security algorithms, the continuous countdown of EV range estimates was found to be inherently ambiguous following continuously changing conditions and the individual stress vulnerability of the drivers (and passengers). Furthermore, the discussion pointed to a rather novel distributed locus of decisionmaking that breached the artificial separation between Foucault's circulation (traveller) and its milieu (security staff) so prevalent in critical security studies, as the drivers were simultaneously object of measurement and subject of nudging but also remained the final arbiter over the trip. Lastly, the range-algorithm discussion drew attention to the layered and mediated observations within this entanglement, and how these observations by non-security personnel not only perform the infrastructure around EVs but also perform particular epistemic or potentially indeterminate forms of uncertainty. This, in turn, opened up the question to what extent security really is the domain of 'security' practitioners.

That said, playing devil's advocate, is all of this truly enough to see range anxiety as a topic worthy of analysis for critical security studies? As stated, range anxiety does not fit popular studied empirical security themes. It lacks obvious threat discourses or a strong power discrepancy between securer and secured, and it misses a sense of urgency and extraordinariness often linked to securitizing moves and matters of life and death - although one can sometimes find a danger logic in discussions in which EVs are situated in extremely remote environments. Similarly, even though risk came up frequently in the discussion above, the range algorithm itself does not adhere to a risk logic, as the estimate is less the outcome of a risk analysis than a continuous countdown that 
informs the (risk) decision of the driver. In fact, the stress-mediated nature of such decisions draws attention to the individual acceptance of risk thresholds - understudied as they are.

The problem is that such critique about the 'securityness' of range anxiety derives from a set of implicit assumptions about what is or is not security. Recent work described security broadly as a 'product of social and political practices' and stated that critical security studies scholars use a plethora of theoretical and methodological approaches - each with their own understanding of security - to study how agents themselves 'problematize' situations and events 'as security problems' (Aradau et al., 2015b: 1, 6). While not asking for always already incomplete content-driven definitions, nor discounting the highly valuable theoretical and methodological work done over the years, an argument can be made that such an approach is vulnerable to self-referential reproductions of particular empirical or theoretical understandings of security.

Coleman and Rosenow (2016: 203, 208) recently made a similar argument. In the context of international development, they draw attention to how those who work to end instances of violent conflict (the insecurity outside observers know and see) often simultaneously hide and (re)confirm the underlying socio-economic 'violences and exclusions' that protect 'business as usual' in these environments. In this line, the above Foucauldian-inspired analysis ignores that EVs also hide a neoliberal institutionalized violence of production (Aradau and Blanke, 2010). Driven by discourses that put prevalence on local particle and global carbon dioxide emissions, EVs re-perform an unsustainable and individualized form of automobility free of local emissions; they generate new supply lines based on mining practices in underdeveloped regions with all the human rights and environmental issues that come with that; and they so far are only marketable through subsidies that primarily benefit the higher well-to-do middle classes and companies able to buy new vehicles (Sovacool et al., 2019; Urry, 2004). However, while definitely worrying, one could argue that Coleman and Rosenow's empirical focus here influences their analysis in turn. Although correct that EVs generate new potential 'violences', these are scrutinized and still open, while electrification moves transport away from the locked-in and well-known violences, exclusions and subsidies behind fossil fuels.

Undoubtedly, a focus on a non-traditional and low-level security practices within sociotechnical systems and their transitions comes with its own blindfolds. But that is not a reason to ignore them. And, as this article shows, there is no doubt that security practices, logics and discourses are affecting and shaping road-based infrastructure and transport systems on both micro and macro levels. This should not be surprising: security practices permeate and mediate the current transitions in energy, food, water, mobility, digitalization, urbanization, and so on - from the resilience logics that drive the development of decentral smart grids to the safety discussions behind air traffic or autonomous vehicles, the risk decisions behind infrastructure maintenance, or the personal security discussions that increasingly play a role in street designs and urban development. Unfortunately, discussions like these are often black-boxed in standardization committees, blueprints, pilot projects, and other research and design formats, and thus generally ignored by critical security scholars. Still, that does not make these security practices weaker or less politically and academically relevant. On the contrary, it reinforces the axiom that the security that we do not see is the security that is most performative of our lives.

\section{Acknowledgements}

Initial versions of this article were written at the Center for Energy Technologies, Department of Business Development and Technology, Aarhus University, Denmark; later revisions were completed in Oxford. The author is appreciative of the insightful comments from two anonymous reviewers and the participants of the 'The Making of (In)Secure Infrastructures' panel at the 2018 Annual Conference of the International Studies Association, in particular Debbie Lisle, as well as the Danish Council for Independent Research for financial 
support. Any opinions, findings, and conclusions or recommendations expressed in this article are those of the author.

\section{Funding}

The author(s) disclosed receipt of the following financial support for the research, authorship, and/or publication of this article: Initial versions of this article were supported by the Danish Council for Independent Research Sapere Aude Grant 4182-00033B 'Societal Implications of a Vehicle-to-Grid Transition in Northern Europe'.

\section{ORCID iD}

Johannes Kester (iD https://orcid.org/0000-0001-5384-0247

\section{Notes}

1. Notably, and counter to its name, range anxiety is not objectless and hence does not really fit the emerging anxiety literature.

2. Personal anecdote.

3. Miles and feet are not converted to kilometres to keep with the US example and speed limits.

\section{References}

Adey P and Anderson B (2011) Anticipation, materiality, event: The Icelandic ash cloud disruption and the security of mobility. Mobilities 6(1): 11-20.

Adey P and Anderson B (2012) Anticipating emergencies: Technologies of preparedness and the matter of security. Security Dialogue 43(2): 99-117.

Åhäll L and Gregory TA (2013) Security, emotions, affect. Critical Studies on Security 1(1): 117-120.

Amicelle A, Aradau C and Jeandesboz J (2015) Questioning security devices: Performativity, resistance, politics. Security Dialogue 46(4): 293-306.

Amoore L and De Goede M (2008) Risk and the War on Terror. London \& New York: Routledge.

Amoore L and Raley R (2017) Securing with algorithms: Knowledge, decision, sovereignty. Security Dialogue 48(1): 3-10.

Anderson B (2010) Preemption, precaution, preparedness: Anticipatory action and future geographies. Progress in Human Geography 34(6): 777-798.

Aradau C (2010) Security that matters: Critical infrastructure and objects of protection. Security Dialogue 41(5): 491-514.

Aradau C (2016) Political grammars of mobility, security and subjectivity. Mobilities 11(4): 564-574.

Aradau C and Blanke T (2010) Governing circulation: A critique of the biopolitics of security. In: De Larrinaga M and Doucet M (eds) Security and Global Governmentality: Globalization, Governance and the State. London: Routledge, 44-58.

Aradau C and Huysmans J (2019) Assembling credibility: Knowledge, method and critique in times of 'posttruth'. Security Dialogue 50(1): 40-58.

Aradau C, Huysmans J, Neal A, et al. (eds) (2015a) Critical Security Methods: New Frameworks for Analysis. London \& New York: Routledge.

Aradau C, Huysmans J, Neal A, et al. (2015b) Introducing critical security methods. In: Aradau C, Huysmans J, Neal A, et al. (eds) Critical Security Methods: New Frameworks for Analysis. London \& New York: Routledge, 1-22.

Baldwin DA (1997) The concept of security. Review of International Studies 23(1): 5-26.

Barad K (2007) Meeting the Universe Halfway: Quantum Physics and the Entanglement of Matter and Meaning. Durham, NC \& London: Duke University Press.

Beauchamps M, Hoijtink M, Leese M, et al. (2017) Introduction: Security/mobility and the politics of movement. In: Leese M and Wittendorp S (eds) Security/Mobility: Politics of Movement. Manchester: Manchester University Press, 1-16. 
Bennett J (2005) The agency of assemblages and the North American blackout. Public Culture 17(3): $445-465$.

Bigo D (2014) The (in)securitization practices of the three universes of EU border control: Military/navy border guards/police - database analysts. Security Dialogue 45(3): 209-225.

Bingham C, Walsh C and Carroll S (2012) Impact of driving characteristics on electric vehicle energy consumption and range. IET Intelligent Transport Systems 6(1): 29-35.

Birrell SA, McGordon A and Jennings PA (2014) Defining the accuracy of real-world range estimations of an electric vehicle. In: 17th International IEEE Conference on Intelligent Transportation Systems (ITSC), 2590-2595.

Booth K (2007) Theory of World Security. Cambridge: Cambridge University Press.

bro1999 (2018) Blissful anniversary Bolt EV road trip? Or fast lane back to the bachelor life? bro05's blog, 4 October. Available at: https://bro05.blogspot.com/2018/10/blissful-anniversary-bolt-ev-road-trip.html (accessed 23 October 2018).

Buekers J, Van Holderbeke M, Bierkens J, et al. (2014) Health and environmental benefits related to electric vehicle introduction in EU countries. Transportation Research Part D: Transport and Environment 33: 26-38.

Butler J (2010) Performative agency. Journal of Cultural Economy 3(2): 147-161.

Buzan B, Wæver O and De Wilde J (1998) Security: A New Framework for Analysis. Boulder, CO: Lynne Rienner.

Callon M (1986) The sociology of an actor-network: The case of the electric vehicle. In: Callon M, Law J and Rip A (eds) Mapping the Dynamics of Science and Technology. Basingstoke: Macmillan, 19-34.

Campbell D (2005) The biopolitics of security: Oil, empire, and the sports utility vehicle. American Quarterly 57(3): 943-972.

Carbon C-C and Gebauer F (2017) The Safe-Range-Inventory (SRI): An assistance tool for optimizing the charging infrastructure for electric vehicles. Transportation Research Part F: Traffic Psychology and Behaviour 47: 101-113.

Coleman LM and Rosenow D (2016) Security (studies) and the limits of critique: Why we should think through struggle. Critical Studies on Security 4(2): 202-220.

Corry O (2012) Securitisation and 'riskification': Second-order security and the politics of climate change. Millennium - Journal of International Studies 40(2): 235-258.

Coward M (2009) Network-centric violence, critical infrastructure and the urbanization of security. Security Dialogue 40(4-5): 399-418.

D'Aoust A-M (2013) Do you have what it takes? Accounting for emotional and material capacities. In: Salter MB and Mutlu CE (eds) Research Methods in Critical Security Studies: An Introduction. London \& New York: Routledge, 33-37.

De Larrinaga M and Doucet M (2010) Introduction: The global governmentalization of security and the securitization of global governance. In: De Larrinaga M and Doucet M (eds) Security and Global Governmentality: Globalization, Governance and the State. London: Routledge.

De Weerdt MM, Stein S, Gerding EH, et al. (2016) Intention-aware routing of electric vehicles. IEEE Transactions on Intelligent Transportation Systems 17(5): 1472-1482.

Dillon M (2005) Global security in the 21st century: Circulation, complexity and contingency. In: The World Today. ISP/NSC Briefing Paper 05/02. London: Chatham House, S1-S8.

Dillon M (2010) Biopolitics of security. In: Burgess JP (ed.) The Routledge Handbook of New Security Studies. London \& New York: Routledge, 61-71.

Eisel M, Nastjuk I and Kolbe LM (2016) Understanding the influence of in-vehicle information systems on range stress: Insights from an electric vehicle field experiment. Transportation Research Part F: Traffic Psychology and Behaviour 43: 199-211.

Elbe S, Roemer-Mahler A and Long C (2014) Securing circulation pharmaceutically: Antiviral stockpiling and pandemic preparedness in the European Union. Security Dialogue 45(5): 440-457.

Enloe C (2014) Bananas, Beaches and Bases, 2nd edn. Berkeley, CA: University of California Press.

Fastrez P and Haué J-B (2008) Designing and evaluating driver support systems with the user in mind. International Journal of Human-Computer Studies 66(3): 125-131. 
Folkman S, Lazarus RS, Gruen RJ, et al. (1986) Appraisal, coping, health status, and psychological symptoms. Journal of Personality and Social Psychology 50(3): 571-579.

Forman PJ (2018) Circulations beyond nodes: (In)securities along the pipeline. Mobilities 13(2): 231-245.

Foucault M (2007) Security, Territory, Population: Lectures at the Collège de France 1977-1978. Ed. Senellart M. New York: Palgrave Macmillan.

Franke T and Krems JF (2013a) Interacting with limited mobility resources: Psychological range levels in electric vehicle use. Transportation Research Part A: Policy and Practice 48: 109-122.

Franke T and Krems JF (2013b) What drives range preferences in electric vehicle users? Transport Policy 30: $56-62$.

Franke T, Neumann I, Bühler F, et al. (2012) Experiencing range in an electric vehicle: Understanding psychological barriers. Applied Psychology 61(3): 368-391.

Franke T, Trantow M, Günther M, et al. (2015) Advancing electric vehicle range displays for enhanced user experience: The relevance of trust and adaptability. In: Proceedings of the 7th International Conference on Automotive User Interfaces and Interactive Vehicular Applications, 249-256.

Geels FW, Sovacool BK, Schwanen T, et al. (2017) Sociotechnical transitions for deep decarbonization. Science 357(6357): 1242-1244.

Genechten BV and Berkhoff AP (2014) Simulation-based design of a steerable acoustic warning device to increase $(\mathrm{H}) \mathrm{EV}$ detectability while reducing urban noise pollution. Proceedings TRA 2014. Available at: https://research.utwente.nl/en/publications/simulation-based-design-of-a-steerable-acoustic-warningdevice-to (accessed 19 February 2018).

Graham-Rowe E, Gardner B, Abraham C, et al. (2012) Mainstream consumers driving plug-in battery-electric and plug-in hybrid electric cars: A qualitative analysis of responses and evaluations. Transportation Research Part A: Policy and Practice 46(1): 140-153.

Habib S, Kamran M and Rashid U (2015) Impact analysis of vehicle-to-grid technology and charging strategies of electric vehicles on distribution networks: A review. Journal of Power Sources 277: 205-214.

Hirsch F (1976) Social Limits to Growth. Cambridge, MA: Twentieth Century Fund.

Hong J, Park S and Chang N (2016) Accurate remaining range estimation for electric vehicles. In: $201621 s t$ Asia and South Pacific Design Automation Conference (ASP-DAC), 781-786.

Huysmans J (2011) What's in an act? On security speech acts and little security nothings. Security Dialogue 42(4-5): 371-383.

International Energy Agency (IEA) (2018) Global EV Outlook 2018: Towards Cross-Modal Electrification. Paris: OECD/International Energy Agency.

International Renewable Energy Agency (IRENA) (2018) Global Energy Transformation: A Roadmap to 2050. Abu Dhabi: IRENA.

Jung MF, Sirkin D, Gür TM, et al. (2015) Displayed uncertainty improves driving experience and behavior: The case of range anxiety in an electric car. In: Proceedings of the 33rd Annual ACM Conference on Human Factors in Computing Systems, 2201-2210.

Kester J (2018a) Governing electric vehicles: Mobilizing electricity to secure automobility. Mobilities 13(2): 200-215.

Kester J (2018b) The Politics of Energy Security: Critical Security Studies, New Materialism and Governmentality. London \& New York: Routledge.

Latour B (1996) Aramis or the Love of Technology. Cambridge, MA: Harvard University Press.

Lazarus RS and Folkman S (1984) Stress, Appraisal, and Coping. New York: Springer.

Leese M and Wittendorp S (2018) The new mobilities paradigm and critical security studies: Exploring common ground. Mobilities 13(2): 171-184.

Liao F, Molin E and Van Wee B (2017) Consumer preferences for electric vehicles: A literature review. Transport Reviews 37(3): 252-275.

Lobo-Guerrero L (2012) Insuring War: Sovereignty, Security and Risk. London \& New York: Routledge.

Loughlan V, Olsson C and Schouten P (2015) Mapping. In: Aradau C, Huysmans J, Neal A, et al. (eds) Critical Security Methods: New Frameworks for Analysis. London \& New York: Routledge, 23-56.

Luhmann N (2006) System as difference. Organization 13(1): 37-57. 
Lundström A (2014) Differentiated driving range: Exploring a solution to the problems with the 'Guess-OMeter' in electric cars. In: Adjunct Proceedings of the 6th International Conference on Automotive User Interfaces and Interactive Vehicular Applications (AutomotiveUI '14), 1-8.

Lundström A and Bogdan C (2012) COPE1: Incorporating coping strategies into the electric vehicle information system. In: Adjunct Proceedings of the 4th International Conference on Automotive User Interfaces and Interactive Vehicular Applications (AutomotiveUI '12), 17-19. Available at https://www.auto-ui. org/12/adjunct-proceedings/wip02-lundstrom.pdf (accessed 26 February 2018).

Massumi B (2007) Potential politics and the primacy of preemption. Theory \& Event 10(2).

McManus MC (2012) Environmental consequences of the use of batteries in low carbon systems: The impact of battery production. Applied Energy 93: 288-295.

Meelen T, Truffer B and Schwanen T (2019) Virtual user communities contributing to upscaling innovations in transitions: The case of electric vehicles. Environmental Innovation and Societal Transitions 31: 96-109.

Methmann C and Rothe D (2012) Politics for the day after tomorrow: The logic of apocalypse in global climate politics. Security Dialogue 43(4): 323-344.

Mitchell T (2013) Carbon Democracy: Political Power in the Age of Oil. London: Verso.

Mol A (2002) The Body Multiple: Ontology in Medical Practice. Durham, NC \& London: Duke University Press.

Nastjuk I and Kolbe L (2015) On the duality of stress in information systems research: The case of electric vehicles. Paper presented at the Thirty Sixth International Conference on Information Systems, Fort Worth, TX, 13-16 December.

Neaimeh M, Hill GA, Hübner Y, et al. (2013) Routing systems to extend the driving range of electric vehicles. IET Intelligent Transport Systems 7(3): 327-336.

Needell ZA, McNerney J, Chang MT, et al. (2016) Potential for widespread electrification of personal vehicle travel in the United States. Nature Energy 1(9): 16112.

Neocleous M (2008) Critique of Security. Edinburgh: Edinburgh University Press.

Neumann I and Krems JF (2016) Battery electric vehicles: Implications for the driver interface. Ergonomics 59(3): 331-343.

Noel L, Zarazua de Rubens G, Sovacool BK, et al. (2019) Fear and loathing of electric vehicles: The reactionary rhetoric of range anxiety. Energy Research \& Social Science 48: 96-107.

Paterson M (2014) Governing mobilities, mobilising carbon. Mobilities 9(4): 570-584.

Paterson M and Dalby S (2006) Empire's ecological tyreprints. Environmental Politics 15(1): 1-22.

Pavlat JW and Diller RW (1993) An energy management system to improve electric vehicle range and performance. IEEE Aerospace and Electronic Systems Magazine 8(6): 3-5.

Pi JM, Bak YS, You YK, et al. (2016) Development of route information based driving control algorithm for a range-extended electric vehicle. International Journal of Automotive Technology 17(6): 1101-1111.

Pichler B and Riener A (2015) Evaluation of historical electric vehicle (EV) driving data to suggest improvements in driving efficiency. In: Adjunct Proceedings of the 7th International Conference on Automotive User Interfaces and Interactive Vehicular Applications (AutomotiveUI '15), 130-135.

Prozorov S (2016) Ex nihilo in mundum: A reply to Paipais. Millennium 45(1): 72-79.

Rauh N, Franke T and Krems JF (2015) Understanding the impact of electric vehicle driving experience on range anxiety. Human Factors 57(1): 177-187.

Rauh N, Franke T and Krems JF (2017) First-time experience of critical range situations in BEV use and the positive effect of coping information. Transportation Research Part F: Traffic Psychology and Behaviour 44: 30-41.

Rezvani Z, Jansson J and Bodin J (2015) Advances in consumer electric vehicle adoption research: A review and research agenda. Transportation Research Part D: Transport and Environment 34: 122-136.

Rotter JB (1966) Generalized expectancies for internal versus external control of reinforcement. Psychological Monographs: General and Applied 80(1): 1-28.

Salter MB (2016) Making Things International 2. Minneapolis, MN: University Of Minnesota Press.

Salter MB and Mutlu CE (eds) (2013) Research Methods in Critical Security Studies: An Introduction. London \& New York: Routledge. 
Shavelson RJ, Hubner JJ and Stanton GC (1976) Self-concept: Validation of construct interpretations. Review of Educational Research 46(3): 407-441.

Sovacool BK, Kester J, Noel L, et al. (2019) Energy injustice and Nordic electric mobility: Inequality, elitism, and externalities in the electrification of vehicle-to-grid (V2G) transport. Ecological Economics 157: 205-217.

Strömberg H, Andersson P, Almgren S, et al. (2011) Driver interfaces for electric vehicles. In: Proceedings of the 3rd International Conference on Automotive User Interfaces and Interactive Vehicular Applications (AutomotiveUI '11), 177-184.

Tannahill VR, Sutanto D, Muttaqi KM, et al. (2015) Future vision for reduction of range anxiety by using an improved state of charge estimation algorithm for electric vehicle batteries implemented with low-cost microcontrollers. IET Electrical Systems in Transportation 5(1): 24-32.

Urry J (2004) The ‘system' of automobility. Theory, Culture \& Society 21(4-5): 25-39.

Ursin H (2011) Cognitive Activation Theory of Stress (CATS). RTO-MP-HFM-205. Brussels: NATO. Available at: https://pdfs.semanticscholar.org/c202/4256e146ac5fd564962b131ceba94f183b71.pdf (accessed 8 March 2018).

Voelkner N (2011) Managing pathogenic circulation: Human security and the migrant health assemblage in Thailand. Security Dialogue 42(3): 239-259.

Zevnik A (2017) From fear to anxiety: An exploration into a new socio-political temporality. Law and Critique 28(3): 235-246.

Johannes Kester is a senior research associate at the Transport Studies Unit of the School of Geography and the Environment at the University of Oxford. He works on the electrification and automation of personal transport as well as the security governance of (road-based) transport through safety, insurance and surveillance practices. Besides recent (co-)authored work published by Palgrave and Routledge, recent publications can be found in Mobilities, EIST, Energy Policy and ERSS. Email: johannes.kester@ouce.ox.ac.uk. 